\title{
DENSIDADE DE PLANTIO E PRODUÇÃO DO MARACUJAZEIRO-AZEDO NO SUL DO BRASIL ${ }^{1}$

\author{
DIEGO WEBER 2 , JONES ELOY ${ }^{2}$, MARCOS ANTÔNIO GIOVANAZ ${ }^{2}$, \\ JOSÉ CARLOS FACHINELLO ${ }^{3}$, JAIR COSTA NACHTIGAL ${ }^{4}$
}

RESUMO - Objetivou-se avaliar a produção e a qualidade dos frutos do maracujazeiro-azedo em relação a diferentes densidades de plantio na região de Pelotas/Rio Grande do Sul/Brasil. O experimento foi conduzido no ciclo de 2011/2012, apenas com plantas de um ano, e no ciclo de 2012/2013, avaliaram-se plantas de um e dois anos. Os tratamentos foram estabelecidos de acordo com as seguintes densidades (plantas ha-1): 1.600 (D1); 2.666; 3.200 (D3). No ciclo de 2012/2013, as plantas de dois anos do tratamento D3 foram desbastadas, permanecendo-se com 1.600 plantas ha $^{-1}$. O tratamento mais adensado, com 3.200 plantas ha $\mathrm{a}^{-1}$ e plantas de um ano, apresentou melhor desempenho produtivo, independentemente do ciclo avaliado. As plantas de dois anos (ciclo de 2012/2013) não demonstraram diferença quanto à produtividade e número de frutos por hectare nas densidades avaliadas. A qualidade dos frutos não foi influenciada pelas densidades de plantio em nenhum ciclo avaliado.

Termos para indexação: Passiflora edulis, maracujá, espaçamento, produtividade, qualidade dos frutos.

\section{PLANTING DENSITY AND YIELD OF SOUR PASSION FRUIT IN SOUTHERN BRAZIL}

\begin{abstract}
The aim was to evaluate the effects of different planting densities of passion fruit on fruit yield and quality in the region of Pelotas/Rio Grande do Sul/Brazil. The experiment was carried out during the 2011/2012 vegetative period only with plants of one year, and during the 2012/2013 vegetative period both plants of one and two years were evaluated. The treatments have been established according to the following planting densities (plants ha-1): 1.600 (D1); 2.666 (D2); 3.200 (D3). ). In the D3 treatment, the plants of two years have been thinned in the 2012/2013 period, remaining 1.600 plants. Independently of the period, the treatment with higher planting density, i.e. 3.200 plants $^{-1} \mathrm{a}^{-1}$ and plants of one year, showed better yield. Two years old plants showed no difference in yield as well as in the number of fruits ha ${ }^{-1}$ between the planting densities, and the fruit quality had been influenced neither by planting densities nor by the vegetative period.
\end{abstract}

Index terms: Passiflora edulis, passion fruit, planting density, yield, fruits quality.

\footnotetext{
${ }_{1}^{1}$ (Trabalho 283-14). Recebido em: 28-10-2014. Aceito para publicação em: 26-06-2015.

${ }^{2}$ Doutorandos, Universidade Federal de Pelotas (UFPel) - Pós-graduação em Agronomia (Fruticultura de Clima Temperado). E-mail: dieweb@gmail.com; joneseloy@yahoo.com.br; giovanazmarcos@gmail.com.

${ }^{3}$ Professor, Dr., Universidade Federal de Pelotas (UFPel) - Pós-graduação em Agronomia (Fruticultura de Clima). E-mail: jfachi@ ufpel.edu.br.

${ }^{4}$ Pesquisador, Dr., Embrapa Clima Temperado. E-mail: jair.nachtigal@embrapa.br
} 


\section{INTRODUÇÃO}

O maracujazeiro pode ser considerado uma alternativa agrícola às pequenas propriedades (três a cinco hectares), considerando que o pequeno produtor atenderá satisfatoriamente às necessidades dos tratos culturais, insumos e exigência de mão de obra, principalmente nas fases da instalação do pomar, polinização manual e colheita do maracujá (MELETTI, 2011; FURLANETO et al., 2014).

A densidade de plantio é influenciada por inúmeros fatores, tais como a topografia, o sistema de sustentação das plantas, o nível de mecanização, a condução das plantas, a associação com outras culturas, a polinização, o vigor das plantas e, sobretudo, pelas condições edafoclimáticas da região de cultivo (PIRES et al., 2011; YAHYA et al., 2013).

Segundo Kist et al. (1995), em sistemas menos adensados, as plantas apresentam maior capacidade produtiva, enquanto o adensamento do maracujazeiro-azedo não acarreta aumento da produtividade por hectare. Por outro lado, Cavichioli et al. (2014) discordam desse ponto, sugerindo maiores densidades de plantio como meio para elevar a produtividade consideravelmente.

A estratégia do adensamento do plantio vem sendo praticada em todo o território brasileiro e possibilita o aumento do volume de ramos produtivos por área, proporcionando assim aumento da produção. Desta forma, os produtores compensam a menor longevidade dos pomares mais adensados pelo aumento e precocidade da produção (SERRA et al., 2013).

Considerando que os relatos experimentais são escassos, no que diz respeito à resposta do maracujazeiro-azedo à densidade de plantio nas condições edafoclimáticas do Rio Grande do SulRS, o presente trabalho objetivou avaliar de que forma diferentes densidades de plantio afetam a produção e a qualidade dos frutos do maracujazeiroazedo na região de Pelotas-RS.

\section{MATERIAL E MÉTODOS}

As mudas de maracujazeiro-azedo (Passiflora edulis Sims) foram provenientes da seleção 'Ovalado Grande', desenvolvida pela Empresa de Pesquisa Agropecuária e Extensão Rural de Santa Catarina (Epagri)/Estação Experimental de Urussanga/Santa Catarina, pelo pesquisador Ademar Brancher. Esta seleção confere plantas vigorosas, frutos grandes e ovalados, de tamanho homogêneo e de dupla aptidão (processamento e consumo in natura), florescimento precoce, época de produção estendida e alta produtividade. É produzido principalmente na região sul de Santa Catarina.

O experimento foi conduzido no Centro Agropecuário da Palma (CAP), Universidade Federal de Pelotas (UFPel), município do Capão do Leão (região de Pelotas-RS,Brasil, latitude $31^{\circ} 52^{\prime} 00^{\prime}$ S, longitude 52 $21^{\prime} 24^{\prime \prime}$ W GRW e 13 metros de altitude. As variáveis foram avaliadas em dois ciclos (2011/2012 e 2012/2013) do cultivo de maracujazeiro-azedo, sendo que no ciclo de 2011/2012 (plantas polinizadas manualmente) avaliaram-se plantas de um ano e no ciclo de 2012/2013 (plantas não polinizadas) avaliaram-se tanto plantas de um como de dois anos.

O clima da região caracteriza-se por ser subtropical úmido com verões quentes do tipo "Cfa", conforme a classificação climática de Köppen, com temperatura e precipitação média anual, em 2012 , de $17,85^{\circ} \mathrm{C}$ e $1.120,6 \mathrm{~mm}$, respectivamente (EAPel, 2015). Dados climatológicos da região são apresentados na Tabela 1.

O solo caracteriza-se como moderadamente profundo com textura média no horizonte $\mathrm{A}$, e argilosa no B, classificados como Argisolo Vermelho-Amarelo. A análise da amostra coletada em 2011 mostra que o solo apresentava 14\% de argila, $1,4 \%$ de matéria orgânica, saturação de alumínio de $14 \%$ e por bases de $49 \%$, CTC em pH 7 de $5 \mathrm{cmol} / \mathrm{dm}^{3}, 39,2 \mathrm{mg} / \mathrm{dm}^{3}$ de P-Mehlich, 67 $\mathrm{mg} / \mathrm{dm}^{3}$ de $\mathrm{K}$ e $\mathrm{pH}$ em água de 5,3. As adubações foram realizadas conforme o Manual de Adubação e Calagem para os Estados do Rio Grande do Sul e Santa Catarina (ROLAS, 2004), aplicando esterco bovino no plantio, doses crescentes de nitrogênio (Ureia) a cada 15-20 dias até ao florescimento, seguido de maiores doses de fósforo (Superfosfato simples) e potássio (Cloreto de Potássio) dividido em cinco parcelas, com base na análise do solo. A calagem foi realizada com calcário dolomítico (PRNT 85\%) realizada conforme o método do índice SMP, elevando o $\mathrm{pH}$ para 6,0, conforme a ROLAS (2004).

O sistema de irrigação adotado foi por gotejamento, com vazão de $2 \mathrm{~L}$ de água $\mathrm{h}^{-1}$ planta $^{-1}$, durante $4 \mathrm{~h} \mathrm{dia}^{-1}$, quando se observou déficit hídrico durante 3 dias consecutivos.

O plantio no ciclo de 2011/2012 foi realizado em 22 de outubro de 2011, com mudas de $40 \mathrm{~cm}$ de altura. Já no ciclo de 2012/2013, foi realizado dia 12 de setembro de 2012, com mudas de $30 \mathrm{~cm}$.

Os tratamentos foram avaliados em dois ciclos - 2011/2012 (plantas de um ano) e 2012/2013 
(plantas de um e dois anos) - em função de três densidades de plantio, havendo variação no espaçamento entre plantas na linha, os quais foram: tratamento D1: distância entre plantas de $2,5 \mathrm{~m}$, utilizando uma planta por cova, densidade de 1.600 plantas por hectare (plantas ha ${ }^{-1}$ ); tratamento D2: distância entre plantas de $1,5 \mathrm{~m}$, utilizando uma planta por cova, densidade de 2.666 plantas ha1; e tratamento D3: distância entre plantas de 2,5 $\mathrm{m}$, utilizando duas plantas por cova, densidade de 3.200 plantas $\mathrm{ha}^{-1}$. Em todos os tratamentos, o espaçamento entre filas foi fixo em 2,5 m. Nos tratamentos D1 e D2, realizou-se a desbrota apical do ramo principal das plantas, enquanto no tratamento D3 as plantas foram conduzidas sem desbrota apical. Em todos os tratamentos, realizouse a desbrota lateral do ramo principal até chegar ao fio de condução (1,80 metro de altura), e a desbrota, quando as plantas encontravam as plantas vizinhas. A colheita foi realizada semanalmente, no período entre abril e agosto (2011/2012) e entre janeiro e agosto $(2012 / 2013)$.

No ciclo de 2012/2013, o tratamento D3 foi desbastado, deixando-se apenas uma planta por cova, de forma a selecionar a planta mais bem formada e com melhor histórico produtivo. Assim, o tratamento D3 com plantas de dois anos apresentou densidade de 1.600 plantas ha ${ }^{-1}$ neste ciclo. As plantas foram podadas no início de setembro de 2012, deixando-se ramos com $60 \mathrm{~cm}$ de comprimento abaixo do fio de condução.

As variáveis de desempenho produtivo avaliadas foram: produtividade $(\mathrm{P})$, em megagrama por hectare $\left(\mathrm{Mg} \mathrm{ha}^{-1}\right)$; produção por planta $(\mathrm{PP})$, em quilo por planta ( $\left.\mathrm{kg}_{\text {planta }}{ }^{-1}\right)$; número de frutos por planta (NFP), em frutos por planta (frutos planta $\left.^{-1}\right)$; número de frutos por hectare (NFH), em frutos por hectare (frutos ha-1). As variáveis físico-químicas dos frutos avaliadas foram: massa média do fruto (MMF), em gramas (g); sólidos solúveis (SS), determinado por refratometria, expresso em ${ }^{\circ}$ Brix; acidez titulável (AT), avaliada por titulometria de neutralização, com diluição de $10 \mathrm{~mL}$ de suco puro em $90 \mathrm{~mL}$ de água destilada e titulação com solução de $\mathrm{NaOH} 0,1 \mathrm{~N}$ até que o suco atingisse $\mathrm{pH} 8,1$, expressa em porcentagem (\%) de ácido cítrico; relação SS/AT (Ratio), determinada através do quociente dos valores de SS e AT; coloração da epiderme (CE), determinada com duas leituras de 9 pontos em cada fruto, através do colorímetro Minolta CR-400, expresso em ângulo hue ( ${ }^{\circ}$ hue) através da expressão: ${ }^{\circ}$ hue $=\tan b * / a *$ ${ }^{1}(+180)$, em que valores $<100=$ amarelo, e $>100$ = verde; espessura do pericarpo (EP), realizaram- se 6 medições com paquímetro digital na parte mediana do fruto, expresso em milímetros ( $\mathrm{mm}$ ); comprimento médio do fruto (CMF), expresso em $\mathrm{mm}$; diâmetro médio do fruto (DMF), expresso em $\mathrm{mm}$; rendimento da polpa (RP), arilo + semente, expresso em porcentagem (\%).

$\mathrm{O}$ delineamento experimental utilizado foi o de blocos casualizados, com três densidades de plantio e cinco repetições. A unidade experimental foi constituída por quatro plantas em linha com bordadura de uma planta, totalizando 20 plantas por tratamento. Para as variáveis físico-químicas dos frutos, em maio de 2012 e 2013, foram colhidos 20 frutos de cada parcela experimental, totalizando assim 100 frutos por tratamento, submetidos às avaliações. Todas as variáveis foram avaliadas para cada ciclo de forma separada. Procedeu-se à análise de variância, utilizando-se do teste $\mathrm{F}(\mathrm{P} \geq 5 \%)$ para a identificação de diferenças significativas entre os tratamentos e, quando o efeito foi significativo, realizou-se teste de comparação de médias (Duncan), ao nível de 5\% de probabilidade de erro. Os dados foram tabulados e interpretados pelo programa estatístico WinStat.

\section{RESULTADOS E DISCUSSÃO}

No primeiro ciclo (2011/2012), houve maior produtividade e maior número de frutos por hectare na maior densidade de plantio (D3 - 3.200 plantas ha $\left.^{-1}\right)$, em relação aos tratamentos D1 (1.600 plantas ha $^{-1}$ ) e D2 (2.666 plantas ha $\left.{ }^{-1}\right)$. O mesmo resultado foi observado no segundo ciclo (2012/2013) para as plantas de um ano, no que se refere à produtividade. Já para o número de frutos por hectare, os tratamentos D2 e D3 foram superiores ao tratamento D1. Assim, constatou-se uma relação diretamente proporcional do número de frutos por hectare e da produtividade com a densidade de plantio. No segundo ciclo (2012/2013), nas plantas de dois anos, não houve diferenças significativas para as variáveis número de frutos por hectare e produtividade, conforme a Tabela 2.

Os resultados corroboram Cavichioli et al. (2014) em Adamantina-P, que observaram aumento da produtividade do maracujazeiro-azedo enxertado em Passiflora gibertii, em resposta ao adensamento de plantas, com melhor desempenho obtido na densidade de 3.525 plantas ha ${ }^{-1}$, produzindo 14,559 $\mathrm{Mg} \mathrm{ha}^{-1}$. Considerou-se, desta forma, que com o adensamento há melhor aproveitamento produtivo das plantas conduzidas em espaldeira, melhor cobertura, interceptação dos raios solares e melhor retorno econômico do investimento. 
Kist et al. (1995), em Porto Lucena-RS, observaram que o número de frutos por hectare não foi influenciado pela densidade de plantio do maracujazeiro-azedo, com média de 103.290 frutos $\mathrm{ha}^{-1}$. Estes autores relatam que a redução do número de plantas por área é compensada pelo aumento da produção de cada planta e, desta forma, a produtividade não é influenciada pelo adensamento.

As plantas, do ciclo de 2012/2013, de um ano, não foram polinizadas manualmente, fato este preponderante para explicar as menores produtividades obtidas neste ciclo, em relação ao ciclo de 2011/2012, no qual as plantas foram polinizadas manualmente. A polinização é um fator indispensável para a produção do maracujá, podendo melhorar consideravelmente a qualidade dos frutos quando realizada a polinização manual ou artificial (MARTINS et al., 2014; PARÉS et al., 2014). Para Krause et al. (2012), a produtividade $\left(5,92 \mathrm{Mg} \mathrm{ha}^{-1}\right)$ das plantas não polinizadas foi $64 \%$ menor que a das plantas polinizadas manualmente $\left(16,41 \mathrm{Mg} \mathrm{ha}^{-1}\right)$.

No ciclo de 2012/2013, as plantas de dois anos produziram consideravelmente mais que as plantas de um ano, mesmo sem a polinização manual, tendo um comportamento produtivo parecido com as plantas do ciclo de 2011/2012. Assim, pode-se considerar que mesmo as plantas de dois anos não polinizadas manualmente produzem mais ou na mesma proporção que as plantas de um ano polinizadas manualmente.

No tratamento D3 (3.200 plantas ha ${ }^{-1}$ ), as plantas foram conduzidas diferentemente das plantas dos tratamentos D1 (1.600 plantas ha $\mathrm{h}^{-1}$ ) e D2 (2.666 plantas ha-1), podendo-se considerar como uma estratégia mais adaptada ao Sul do Brasil na primeira safra.

Segundo Ritzinger et al. (1989), em ViamãoRS, a densidade de plantio mais produtiva foi de 2.000 plantas ha $^{-1}(2,0 \times 2,5 \mathrm{~m})$, com produtividade $70 \%$ superior à menor densidade de plantio testada, de 695 plantas ha-1 $(5,75 \times 2,5 \mathrm{~m})$. Estes resultados foram semelhantes aos valores de produtividade encontrados neste trabalho, no qual houve um aumento de 52\% (ciclo de 2011/2012) e 53\% (ciclo de 2012/2013 em plantas de um ano) na produtividade da maior densidade de plantio, 3.200 plantas ha-1 (D3), em relação à menor, de 1.600 plantas ha-1 (D1).

Apesar disso, nos ciclos de 2011/2012 e 2012/2013 (plantas de um ano), não houver dificuldades na realização dos tratos culturais, nas aplicações de agrotóxicos e na polinização manual, nos tratamentos mais adensados: D2 (2.666 plantas ha-1) e D3 (3.200 plantas ha-1). Já no ciclo de 2012/2013, as plantas de dois anos apresentaram alto vigor na maior densidade (2.666 plantas ha ${ }^{-1}$ ), com dificuldades de pulverizações no interior da planta e alto sombreamento dos ramos produtivos.

Houve comportamento semelhante entre as variáveis produção por planta e número de frutos por planta. Considerando estas variáveis, no ciclo de 2011/2012, o tratamento D1 (1.600 plantas ha ${ }^{-1}$ ) foi superior aos demais (D2 - 2.666 plantas ha-1 $^{-1}$ D3 - 3.200 plantas ha-1). No ciclo de 2012/2013, para as plantas de um ano, não houve diferença entre as densidades; provavelmente, a ausência da polinização manual está muito relacionada com menor número de flores fecundadas por planta e, consequentemente, menores produções por planta. Para as plantas de dois anos (ciclo de 2012/2013), na densidade de 1.600 plantas ha $^{-1}$ (D1 e D3), as produções foram superiores em relação à maior densidade (D2 - 2.666 plantas ha ${ }^{-1}$ ).

De acordo com Cavichioli et al. (2014), em plantios adensados, observa-se menor número de frutos por planta. Isto pode estar relacionado à menor fecundação de flores, diminuição da eficiência da polinização devido ao alto sombreamento dos ramos e, também, podendo causar a diminuição da taxa fotossintética líquida.

Para os sólidos solúveis, não houve diferença estatística significativa entre os tratamentos em nenhum dos ciclos avaliados, conforme a Tabela 3, corroborando Ritzinger et al. (1989), que não observaram diferenças dos teores de sólidos solúveis em função do adensamento. Em geral, Aguiar et al. (2015) observaram valores maiores de sólidos solúveis, com média variando de 13,7 a $15,4^{\circ}$ Brix.

Não houve diferenças estatísticas significativas para a acidez titulável entre os tratamentos para nenhum dos ciclos avaliados, de acordo com a TABELA 3, corroborando Araújo Neto et al. (2005), que encontraram resultados que mostram que a acidez titulável do fruto não foi influenciada pela densidade de plantio, com variação de $4,31 \%$ a $5,25 \%$ na primeira safra, e de $4,61 \%$ a $5,47 \%$ na segunda safra.

Conforme Santos et al. (2013), os frutos do maracujazeiro-amarelo BRS Gigante Amarelo, colhidos maduros, apresentaram média de acidez total de 3,88\%. Com baixas temperaturas e alta amplitude térmica na maturação dos frutos, o ácido cítrico tende a acumular-se. Assim, explica-se a alta acidez titulável $(5,60 \%)$ observada nas condições de Pelotas-RS, para o maracujazeiro-azedo.

Não houve diferenças estatísticas 
significativas para a variável RATIO entre as densidades de plantio, em nenhum dos ciclos avaliados, conforme a Tabela 3. Podem-se explicar os baixos valores de RATIO, pelo fato de a acidez titulável elevada correlacionar-se negativamente com o RATIO. Da mesma forma, não houve diferenças significativas para a coloração da epiderme e a espessura do pericarpo entre as densidades de plantio para todos os ciclos avaliados (Tabela 3).
De acordo com a Tabela 3, não houve diferenças estatísticas significativas para a massa média do fruto e o diâmetro médio do fruto, da mesma forma como observado por Cavichioli et al. (2014). Também não houve diferenças significativas para o rendimento de polpa e o comprimento médio do fruto, entre as densidades de plantio estudadas para todos os ciclos avaliados.

TABELA 1 - Dados climáticos da Estação Agroclimatológica de Pelotas-RS, para os anos de 2011, 2012 e 2013

\begin{tabular}{|c|c|c|c|c|c|c|c|c|c|c|}
\hline Mês & Ano & $\mathrm{TA}$ & $\mathrm{TM}$ & $\mathrm{Tm}$ & UR & $\mathrm{A}$ & $\mathrm{RS}$ & $\mathrm{I}$ & $\mathrm{P}$ & NDG \\
\hline \multirow{2}{*}{ Setembro } & 2011 & 14,4 & 20,0 & 10,1 & 81,8 & 9,9 & 331,8 & 199,6 & 75,1 & 6,0 \\
\hline & 2012 & 16,2 & 21,3 & 12,3 & 81,1 & 8,9 & 309,9 & 176,1 & 115,3 & 0 \\
\hline \multirow{2}{*}{ Outubro } & 2011 & 17,4 & 22,1 & 13,5 & 81,2 & 8,7 & 349,1 & 187,0 & 75,9 & 0 \\
\hline & 2012 & 19,2 & 23,6 & 15,9 & 81,2 & 7,8 & 338,5 & 160,8 & 106,5 & 0 \\
\hline \multirow{2}{*}{ Novembro } & 2011 & 19,8 & 25,3 & 15,1 & 76,3 & 10,2 & 524,5 & 281,3 & 60,3 & 0 \\
\hline & 2012 & 21,2 & 27,0 & 16,6 & 76,0 & 10,5 & 504,8 & 280,8 & 52,1 & 0 \\
\hline \multirow{2}{*}{ Dezembro } & 2011 & 20,6 & 26,0 & 16,2 & 79,0 & 9,8 & 494,2 & 254,0 & 53,7 & 0 \\
\hline & 2012 & 23,6 & 29,3 & 18,7 & 75,3 & 10,6 & 502,0 & 257,1 & 175,1 & 0 \\
\hline \multirow{2}{*}{ Janeiro } & 2012 & 22,7 & 28,4 & 17,9 & 78,3 & 10,5 & 549,5 & 300,5 & 73,6 & 0 \\
\hline & 2013 & 22,3 & 27,5 & 17,5 & 76,5 & 10,0 & 548,5 & 299,7 & 69,2 & 0 \\
\hline \multirow{2}{*}{ Fevereiro } & 2012 & 24,2 & 29,8 & 20,2 & 82,2 & 9,7 & 435,2 & 213,0 & 171,9 & 0 \\
\hline & 2013 & 22,8 & 28 & 19,1 & 81,4 & 9,0 & 454,9 & 220,7 & 177,3 & 0 \\
\hline \multirow{2}{*}{ Março } & 2012 & 21,5 & 28,1 & 16,6 & 80,9 & 11,5 & 416,8 & 259,2 & 49,0 & 0 \\
\hline & 2013 & 19,8 & 25,8 & 15,2 & 80,4 & 10,6 & 390,4 & 234,5 & 27,6 & 0 \\
\hline \multirow{2}{*}{ Abril } & 2012 & 17,4 & 23,7 & 12,8 & 81,9 & 10,9 & 300,8 & 198,2 & 52,4 & 1 \\
\hline & 2013 & 18,6 & 24,5 & 13,8 & 82,3 & 10,6 & 306,7 & 216,3 & 147,4 & 0 \\
\hline \multirow{2}{*}{ Maio } & 2012 & 16,8 & 23,9 & 12,2 & 84,1 & 11,8 & 255,0 & 218,4 & 5,1 & 1 \\
\hline & 2013 & 14,6 & 20,6 & 10,5 & 85,0 & 10,1 & 211,8 & 162,7 & 84,1 & 3 \\
\hline \multirow{2}{*}{ Junho } & 2012 & 12,3 & 19,5 & 7,3 & 82,0 & 12,2 & 196,4 & 171,1 & 78,0 & 7 \\
\hline & 2013 & 12,5 & 18,4 & 8,0 & 84,6 & 10,4 & 202,9 & 170,0 & 75,8 & 2 \\
\hline \multirow{2}{*}{ Julho } & 2012 & 10,4 & 16,8 & 5,6 & 81,4 & 11,2 & 221,7 & 197,5 & 138,5 & 10 \\
\hline & 2013 & 11,6 & 17,8 & 7,2 & 83,7 & 10,6 & 210,2 & 181,3 & 56,6 & 8,0 \\
\hline \multirow{2}{*}{ Agosto } & 2012 & 16,7 & 22,9 & 12,6 & 84,1 & 10,3 & 263,3 & 195,3 & 103,1 & 0 \\
\hline & 2013 & 11,3 & 17,1 & 7,0 & 83,7 & 10,2 & 227,7 & 155,1 & 95,3 & 7 \\
\hline
\end{tabular}

$\mathrm{TA}=$ Temperatura média diária $\left({ }^{\circ} \mathrm{C}\right) ; \mathrm{TM}=$ Temperatura máxima $\left({ }^{\circ} \mathrm{C}\right) ; \mathrm{Tm}=$ Temperatura mínima $\left({ }^{\circ} \mathrm{C}\right) ; \mathrm{UR}=$ Umidade relativa $(\%) ; \mathrm{A}$ $=$ Amplitude $\left({ }^{\circ} \mathrm{C}\right) ; \mathrm{RS}=$ Radiação solar $\left(\mathrm{cal} \mathrm{cm}^{-2} \mathrm{dia}^{-1}\right) ; \mathrm{I}=$ Insolação (horas e décimos $) ; \mathrm{P}=$ Precipitação pluviométrica $(\mathrm{mm}) ; \mathrm{NDG}=$ Número de dias de geada. Fonte: EAPel (2013). 
TABELA 2- Produtividade (P), produção por planta (PP), número de frutos por planta (NFP) e número de frutos por hectare (NFH) do maracujazeiro-azedo, seleção 'Ovalado Grande' da Epagri, em função de três densidades de plantio. UFPel/FAEM, Pelotas-RS, 2014.

\begin{tabular}{|c|c|c|c|c|c|}
\hline \multirow{2}{*}{$\begin{array}{l}\text { Densidade de plantio } \\
\quad\left(\text { plantas } \mathrm{ha}^{-1}\right)\end{array}$} & \multirow{2}{*}{$\begin{array}{c}\text { Espaçamento entre } \\
\text { plantas x entre linhas } \\
\text { (metros) }\end{array}$} & \multicolumn{2}{|c|}{ Produção } & \multicolumn{2}{|c|}{ Número de frutos } \\
\hline & & \multicolumn{2}{|c|}{$\operatorname{Mg~ha}^{-1}(\mathrm{P}) \mathrm{kg}_{\text {planta }}{ }^{-1}(\mathrm{PP})$} & $\begin{array}{l}\text { Frutos planta }^{-1} \\
\text { (NFP) }\end{array}$ & $\begin{array}{l}\text { Frutos ha }^{-1} \\
\text { (NFH) }\end{array}$ \\
\hline \multicolumn{6}{|c|}{ Ciclo de 2011/2012 } \\
\hline $1.600(\mathrm{D} 1)$ & $2,5 \times 2,5$ & $16,66 \mathrm{~B}$ & $10,41 \mathrm{~A}$ & $43,01 \mathrm{~A}$ & $68.816 \mathrm{~B}$ \\
\hline $2.666(\mathrm{D} 2)$ & $1,5 \times 2,5$ & 20,24B & $7,60 \mathrm{~B}$ & $31,58 \mathrm{~B}$ & 84.192B \\
\hline $3.200(\mathrm{D} 3)$ & $2,5 \times 2,5^{1}$ & $25,44 \mathrm{~A}$ & $7,95 \mathrm{~B}$ & $31,85 \mathrm{~B}$ & $101.920 \mathrm{~A}$ \\
\hline Média geral & ------ & 20,78 & 8,65 & 35,48 & 84.976 \\
\hline CV $(\%)$ & ------ & 15,87 & 15,30 & 15,56 & 9,67 \\
\hline $\mathrm{F}$ & ------ & 8,96 & 6,72 & 6,00 & 5,18 \\
\hline \multicolumn{6}{|c|}{ Ciclo de 2012/2013 - plantas de um ano } \\
\hline $1.600(\mathrm{D} 1)$ & $2,5 \times 2,5$ & $10,31 \mathrm{~B}$ & 6,44 & 25,90 & $41.440 \mathrm{~B}$ \\
\hline $2.666(\mathrm{D} 2)$ & $1,5 \times 2,5$ & $13,97 \mathrm{~B}$ & 5,24 & 21,04 & $56.092 \mathrm{~B}$ \\
\hline $3.200(\mathrm{D} 3)$ & $2,5 \times 2,5^{1}$ & $19,20 \mathrm{~A}$ & 6,00 & 24,99 & $79.968 \mathrm{~A}$ \\
\hline Média geral & ------ & 14,49 & 5,89 & 23,97 & 59.166 \\
\hline $\mathrm{CV}(\%)$ & ------ & 17,67 & 14,45 & 17,17 & 15,23 \\
\hline $\mathrm{F}$ & ------ & 6,18 & ns & ns & 4,48 \\
\hline \multicolumn{6}{|c|}{ Ciclo de 2013/2013 - plantas de dois anos } \\
\hline $1.600(\mathrm{D} 1)$ & $2,5 \times 2,5$ & 23,26 & $14,54 \mathrm{~A}$ & $58,40 \mathrm{~A}$ & 93.440 \\
\hline $2.666(\mathrm{D} 2)$ & $1,5 \times 2,5$ & 23,16 & $8,68 \mathrm{~B}$ & $35,89 \mathrm{~B}$ & 95.682 \\
\hline $1.600(\mathrm{D} 3)$ & $2,5 \times 2,5$ & 26,05 & $16,28 \mathrm{~A}$ & $66,40 \mathrm{~A}$ & 106.240 \\
\hline Média geral & ------ & 24,15 & 13,16 & 52,89 & 99.120 \\
\hline $\mathrm{CV}(\%)$ & ------ & 12,54 & 12,53 & 22,53 & 16,11 \\
\hline $\mathrm{F}$ & ------ & ns & 7,35 & 9,07 & $\mathrm{~ns}$ \\
\hline
\end{tabular}

${ }^{1}$ Duas mudas por cova. *Teste $\mathrm{F}(\mathrm{P} \geq 5 \%)$ *Valores seguidos de mesma letra não diferenciam significativamente entre si na coluna, pelo teste de Duncan, a 5\% de probabilidade de erro. ns = não significativo. 
TABELA 3 - Sólidos solúveis (SS), acidez titulável (AT), Relação SS/AT (RATIO), coloração da epiderme (CE), massa média do fruto (MF), espessura do pericarpo (EP), comprimento médio do fruto (CMF); diâmetro médio do fruto (DMF) e rendimento de polpa (RP) do maracujazeiroazedo, seleção 'Ovalado Grande' da Epagri, em função de três densidades de plantio. UFPel/ FAEM, Pelotas-RS, 2014.

\begin{tabular}{|c|c|c|c|c|c|c|c|c|}
\hline $\begin{array}{l}\text { Densidade } \\
\text { de plantio } \\
\left(\text { plantas ha }{ }^{-1}\right)\end{array}$ & $\begin{array}{l}\text { Espaçamento } \\
\text { entre plantas SS } \\
\text { x entre linhas }\left({ }^{\circ} \mathrm{Brix}\right) \\
\quad(\text { metros })\end{array}$ & $\begin{array}{l}\text { AT } \\
\text { (\% ác. } \\
\text { cítrico) }\end{array}$ & RATIO CE ( $\left.{ }^{\circ} \mathrm{Hue}\right)$ & $\begin{array}{l}\text { MF } \\
(\mathrm{kg})\end{array}$ & $\begin{array}{c}\text { EP } \\
(\mathrm{mm})\end{array}$ & $\begin{array}{l}\text { CMF } \\
(\mathrm{mm})\end{array}$ & $\begin{array}{l}\text { DMF } \\
(\mathrm{mm})\end{array}$ & $\begin{array}{l}\text { RP } \\
(\%)\end{array}$ \\
\hline
\end{tabular}

\begin{tabular}{|c|c|c|c|c|c|c|c|c|c|c|}
\hline \multirow[b]{2}{*}{$1.600(\mathrm{D} 1)$} & \multicolumn{10}{|c|}{ Ciclo de 2011/2012 } \\
\hline & $2,5 \times 2,5$ & 11,33 & 5,48 & 2,02 & 106,09 & 0,242 & 5,96 & 101,81 & 86,07 & 52,13 \\
\hline 2.666 (D2) & $1,5 \times 2,5$ & 11,07 & 5,11 & 2,17 & 108,50 & 0,240 & 5,53 & 100,32 & 86,03 & 51,40 \\
\hline 3.200 (D3) & $2,5 \times 2,5^{1}$ & 11,36 & 6,22 & 1,85 & 108,39 & 0,249 & 5,72 & 119,76 & 84,09 & 50,73 \\
\hline Média geral & ------ & 11,25 & 5,60 & 2,01 & 107,66 & 0,243 & 5,73 & 107,30 & 85,39 & 51,42 \\
\hline CV $(\%)$ & ------ & 5,97 & 11,09 & 12,22 & 4,17 & 10,77 & 12,44 & 15,78 & 4,60 & 12,09 \\
\hline $\mathrm{F}$ & ------ & ns & ns & ns & ns & ns & ns & 115 & ns & ns \\
\hline \multicolumn{11}{|c|}{ Ciclo de 2012/2013 - plantas de um ano } \\
\hline 1.600 (D1) & $2,5 \times 2,5$ & 12,43 & 6,54 & 1,90 & 98,02 & 0,249 & 6,01 & 120,69 & 88,78 & 49,01 \\
\hline $2.666(\mathrm{D} 2)$ & $1,5 \times 2,5$ & 12,91 & 5,56 & 2,32 & 100,05 & 0,248 & 5,59 & 118,75 & 84,44 & 53,22 \\
\hline 3.200 (D3) & $2,5 \times 2,5^{1}$ & 12,04 & 5,69 & 2,11 & 99,19 & 0,240 & 5,78 & 121,31 & 85,13 & 51,11 \\
\hline Média geral & ------ & 12,46 & 5,93 & 2,11 & 99,08 & 0,245 & 5,79 & 120,25 & 86,11 & 51,11 \\
\hline $\mathrm{CV}(\%)$ & ------ & 6,01 & 7,71 & 8,50 & 9,13 & 14,64 & 5,97 & 10,12 & 7,40 & 11,93 \\
\hline $\mathrm{F}$ & ------ & ns & ns & ns & ns & ns & ns & ns & ns & ns \\
\hline \multicolumn{11}{|c|}{ Ciclo de 2013/2013 - plantas de dois anos } \\
\hline $1.600(\mathrm{D} 1)$ & $2,5 \times 2,5$ & 12,81 & 6,02 & 2,12 & 102,02 & 0,248 & 4,87 & 101,22 & 79,54 & 53,45 \\
\hline 2.666 (D2) & $1,5 \times 2,5$ & 11,98 & 5,43 & 2,20 & 101,17 & 0,241 & 5,52 & 111,38 & 82,51 & 51,50 \\
\hline 3.200 (D3) & $2,5 \times 2,5$ & 12,57 & 6,42 & 1,95 & 99,99 & 0,245 & 5,64 & 109,80 & 83,47 & 53,36 \\
\hline Média geral & ------ & 12,45 & 5,95 & 2,09 & 101,06 & 0,244 & 5,34 & 107,46 & 81,84 & 52,77 \\
\hline CV (\%) & ------ & 10,08 & 5,64 & 7,77 & 3,73 & 12,79 & 12,15 & 11,50 & 9,31 & 6,82 \\
\hline $\mathrm{F}$ & ------ & ns & ns & ns & ns & ns & ns & ns & ns & ns \\
\hline
\end{tabular}

${ }^{1}$ duas mudas por cova. $*$ Teste $\mathrm{F}(\mathrm{P} \geq 5 \%)$ *Valores seguidos de mesma letra não diferenciam significativamente entre si na coluna, pelo teste de Duncan, a 5\% de probabilidade de erro. ns = não significativo.

\section{CONCLUSÕES}

Foi possível constatar que a densidade de plantio do maracujazeiro-amarelo mais adaptada ao Sul do Brasil, com maior rendimento produtivo, é a de 3.200 plantas por hectare. dos frutos.

A densidade de plantio não altera a qualidade

\section{REFERÊNCIAS}

AGUIAR, R.S.F.; ZACCHEO, P.V.C.; STENZEL, N.M.C.; SERA, T.; NEVES, C. Produção e qualidade de frutos híbridos de maracujazeiroamarelo no norte do Paraná. Revista Brasileira de Fruticultura, Jaboticabal, v.37, n.1, p.130-137, 2015. 
ARAÚJO NETO, S.E. de; RAMOS, J.D.; ANDRADE JÚNIOR, V.C. de; RUFINI, J.C.M.; MENDONÇA, V.; OLIVEIRA, T.K.de. Adensamento, desbaste e análise econômica na produção do maracujazeiro-amarelo. Revista Brasileira de Fruticultura, Jaboticabal, v.27, n.3, p.394-398, 2005.

CAVICHIOLI, J.C.de; KASAI, F.S.; NASSER, M.D. Produtividade e características físicas de frutos de Passiflora edulis enxertado sobre Passiflora gibertii em diferentes espaçamentos de plantio. Revista Brasileira de Fruticultura, Jaboticabal, v.36, n.1, p.243-247. 2014.

EAPEL. Estação agroclimática de Pelotas. Disponível em: <www.cpact.embrapa.br/agromet/ estacao/estacao.html>. Acesso em: 16 jun. 2015.

FURLANETO, F. de P.B.; ESPERANCINI, M.S.T.; MARTINS, A.N.; OKAMOTO, F. VIDAL, A. de A.; BUENO, O. de C. Análise energética do novo sistema de produção de maracujá amarelo na região de Marília-SP. Ciência Rural, Santa Maria, v.44, n.2, p.235-240, 2014.

KIST, H.G.K.; MANICA, I.; BOARO, A. Efeito de seis espaçamentos de plantio na produção do maracujá-amarelo (Passiflora edulis f. flavicarpa Deg.) em Porto Lucena/RS. Pesquisa Agropecuária Gaúcha, Porto Alegre, v.1, n.1, p.21-26, 1995.

KRAUSE, W.; NEVES, L.G.; VIANA, A.P.; ARAÚJO, C.A.T.; FALEIRO, F.G. Produtividade e qualidade de frutos de cultivares de maracujazeiro-amarelo com ou sem polinização artificial. Pesquisa Agropecuária Brasileira, Brasília, v.47, n.12, p.1737-1742, 2012.

MARTINS, M.R.; REIS, M.C.dos; ARAUJO, J.R.G.; LEMOS, R.N.S.de; COELHO, F.A.O. Tipos de polinização e pastejo da abelha Xylocopa spp. na frutificação e qualidade dos frutos de maracujazeiro. Revista Caatinga, Mossoró, v.27, n.1, p.187-193, 2014
MELETTI, L.M.M. Avanços na cultura do maracujá no Bra(1)sil. Revista Brasileira de Fruticultura, Jaboticabal, vol.33, n.spe1, p.83-91, 2011.

PARÉS，J.; SÁNCHEZ, J.; ARIZALETA, M. Efecto de la polinización artificial sobre la fructificación y la calidad de fruto del maracuyá amarillo (Passiflora edulis f. flavicarpa Deg.). Bioagro, Barquisimeto, v.26, n.3, 2014.

PIRES, M.M.; SÃO JOSÉ, A.R.; CONCEIÇÃO, A.O. Maracujá: avanços tecnológicos e sustentabilidade. Bahia: Editus, 2011. p.237.

RITZINGER, R.; MANICA， I.; RIBOLDI， J Efeito do espaçamento e da época de colheita sobre a qualidade do maracujá amarelo. Pesquisa Agropecuária Brasileira, Brasília, v.24, n.2, p.241-245, 1989.

ROLAS - Rede Oficial de Laboratórios de Análise de Solo e de Tecido Vegetal. Manual de adubação e calagem para os estados do Rio Grande do Sul e Santa Catarina.10.ed. Porto Alegre: Sociedade Brasileira de Ciência do Solo, 2004. 400p.

SANTOS, J.L.V.dos; RESENDE， E.D.de; MARTINS, D.R.; GRAVINA, G.deA.; CENCI, S.A.; MALDONADO, J.F.M. Determinação do ponto de colheita de diferentes cultivares de maracujá. Revista Brasileira de Engenharia Agrícola e Ambiental, Campina Grande, v.17, n.7, p. $750-755,2013$.

SERRA, E.L.; SCALCO, M.S.; GUIMARÃES, R.J.; COLOMBO, A.; MORAIS, A.R. de; CARVALHO, C.H.M. de. Production functions of irrigated coffee under different planting densities. Coffee Science, Lavras, v.8, n.2, p.149-157, 2013.

YAHYA, A.; TAJUDEEN, K.; ISHOLA, A.; SURYANTO, H. Physical and mechanical properties of Jatropha curcas 1. Fruits from different planting densities. Journal of Applied Sciences, Muzaffarpur, v.13, n.7, p.1004-1012, 2013. 